\title{
DNA-PKcs inhibitor increases the sensitivity of gastric cancer cells to radiotherapy
}

\author{
WEI GENG ${ }^{1}$, DALONG TIAN ${ }^{1}$, QIANG WANG ${ }^{2}$, SHUNLIN SHAN ${ }^{1}$, \\ JIANWEI ZHOU ${ }^{3}$, WENXIA XU ${ }^{2}$ and HUSHENG SHAN ${ }^{3}$ \\ ${ }^{1}$ Yancheng City No. 1 People's Hospital, Yancheng, Jiangsu 224005; ${ }^{2}$ Department of Molecular Cell Biology \\ and Toxicology, School of Public Health, Nanjing Medical University, Nanjing, Jiangsu 211166; \\ ${ }^{3}$ Cancer Center of The 82nd Hospital of PLA, Huaian, Jiangsu 223001, P.R. China
}

Received May 18, 2018; Accepted May 23, 2019

DOI: $10.3892 /$ or.2019.7187

\begin{abstract}
Gastric cancer (GC) is a severe public health problem worldwide, particularly in China. Radiotherapy is the main locoregional treatment for various types of unresectable tumor, including GC. However, many patients fail to respond to radiotherapy due to the intrinsic radioresistance of cancer cells. This study was designed to investigate the effects and potential mechanism of radiosensitization associated with DNA-dependent protein kinase catalytic subunit (DNA-PKcs) inhibitor in human GC cell lines in vitro. Among the six GC cell lines (SGC7901, HGC-27, MKN45, MKN74, BGC823 and MGC803) that were exposed to increasing doses of IR $(0,2,4,6$ and $8 \mathrm{~Gy})$, the mean lethal dose and quasi-threshold dose measurements indicated that BGC823 and MGC803 were relatively insensitive to ionizing radiation (IR). IR induced significant elevation of $\gamma \mathrm{H} 2 \mathrm{~A}$ histone family member $\mathrm{X}(\gamma \mathrm{H} 2 \mathrm{AX})$ in MKN45 cells compared with BGC823 cells. DNA-PKcs and phospho-DNA-PKcs protein levels were increased in BGC823 and MGC803 cells compared with other GC cell lines (SGC7901, HGC-27, MKN45 and MKN74). DNA-PKcs inhibition led to increased sensitivity of BGC823 and MGC803 cells to IR. NU7441 increased $\gamma \mathrm{H} 2 \mathrm{AX}$ expression in the nuclei of BGC823 cells following IR. Combination of DNA-PKcs and CK2 inhibition further increased the sensitivity of GC cells to IR. The combination of NU7441 and CX4945 increased $\gamma \mathrm{H} 2 \mathrm{AX}$ expression in the nucleus of BGC823 cells following IR compared with treatment with NU7441 alone. Taken together, the findings suggest that DNA-PKcs inhibitor increased the sensitivity of radioresistant $\mathrm{BGC} 823$ and $\mathrm{MGC} 803$ cells to radiotherapy
\end{abstract}

Correspondence to: Dr Husheng Shan, Cancer Center of The 82nd Hospital of PLA, 100 Jiankang Road, Huaian, Jiangsu 223001, P.R. China

E-mail: shanhushengcc@sina.com

Key words: radiotherapy resistance, gastric cancer, DNA-dependent protein kinase catalytic subunit inhibitor through the cleaved-caspase $3 / \gamma \mathrm{H} 2 \mathrm{AX}$ signaling pathway, thus presenting a potential treatment method for GC.

\section{Introduction}

Gastric cancer (GC) is the fourth most common type of cancer globally, with high frequency and mortality rates (1). GC remains one of the most severe public health problems worldwide, and particularly in China (2). Therefore, it is necessary to explore potential novel therapeutic methods for treating GC.

Classical adjuvant treatment methods for patients with GC are based on MacDonald's protocol, combining 5-fluoruracil (5-FU) and radiation in patients with stage IB-IVA, which is associated with increased progression free survival (PFS) and overall survival (OS) of patients with GC $(3,4)$.

Radiotherapy is the major loco-regional control method for unresectable GC. Unfortunately, intrinsic radio-resistance of cells results in failure of radiotherapy in numerous patients (5). The guidelines of the National Comprehensive Cancer Network recommend radiotherapy as a standard therapy for patients with GC. There are two major limitations associated with treating GC via radiation: Intrinsic or acquired resistance to radiotherapy, and nonspecific toxicity to gastric mucosa and the surrounding normal tissues $(6,7)$. For instance, radiotherapy is routinely used for treating cancer and generates various DNA lesions, which in turn activates the DNA damage response (8).

DNA double strand breaks (DSBs) are generated by ionizing radiation (IR), and can be repaired by non-homologous end-joining (NHEJ) and homologous recombination $(9,10)$. DNA-dependent protein kinase catalytic subunit (DNA-PKcs) is a crucial factor involved in NHEJ, and the DNA-PK complex contributes to early-stage damage-induced DNA repair (11). DNA-PKcs expression predicts response to radiotherapy in patients with prostate cancer (12). Silencing of DNA-PKcs leads to increased radiosensitivity and DSBs $(13,14)$. Overexpression of DNA-PKcs in patients with nasopharyngeal carcinoma has been reported to be associated with a relatively poor clinical outcome (15). Silence and loss-of-function mutations of DNA-PKcs were demonstrated to promote apoptosis resistance in a number of types of cancer cells, including head and neck cancer, leukemia and skin cells (16-18). 
Thus, DNA-PK may be a radiotherapeutic target for cancer. In the current study, the function of a DNA-PKcs inhibitor in GC cell lines, and the corresponding molecular mechanisms were investigated, aiming to identify a potential novel treatment method for GC.

\section{Materials and methods}

Cell culture. Human BGC823, SGC7901, MGC803, HGC-27, MKN45 and MKN74 GC cell lines were obtained from Shanghai Institute of Cell Biology (Shanghai, China) and cultured in RPMI-1640 medium, supplemented with $10 \%$ calf bovine serum, $50 \mathrm{U} / \mathrm{ml}$ penicillin and $50 \mathrm{U} / \mathrm{ml}$ streptomycin in an incubator at $37^{\circ} \mathrm{C}$ in $5 \% \mathrm{CO}_{2}$.

Ionizing radiation. The DNA-PK inhibitor NU7441 (Tocris Bioscience, Bristol, UK) was dissolved in dimethyl sulfoxide (DMSO) as a $5 \mathrm{mmol} / \mathrm{l}$ stock solution and stored at $-20^{\circ} \mathrm{C}$. A casein kinase 2 (CK2) inhibitor, CX4945, was purchased from Selleck Chemicals (Houston, TX, USA). Cells were exposed to X-rays generated by a Rad Source RS2000 irradiator ( $\mathrm{Rad}$ Source Technologies, Inc., Buford, GA, USA) operating at $25 \mathrm{~mA}$ with a $0.3 \mathrm{~mm} \mathrm{Al}$ filter and effective photon energy of $160 \mathrm{kV}$. The dose rate at an irradiation distance of $48.6 \mathrm{~cm}$ was $1.31 \mathrm{~Gy} / \mathrm{min}$.

Clonogenic survival assay. Cells were seeded into 6-well plates $\left(2 \times 10^{6}\right)$ and treated with or without drug $(0.1 \mu \mathrm{M}$ NU7441 or $0.5 \mu \mathrm{M}$ CX4945) following attachment for 4-6 h. The next day, the cells were exposed to different doses of IR. Cells were incubated for 10-14 days to form colonies, then fixed with $100 \%$ methyl alcohol for $5 \mathrm{~min}$ and stained with $1 \%$ crystal violet for $10 \mathrm{~min}$ at room temperature. Colonies containing $>50$ cells were counted. Survival fractions were normalized according to the non-irradiated subgroup to eliminate cytotoxicity generated by drug pretreatment. Cell survival curves were obtained using GraphPad Prism 7 software (GraphPad Software, Inc., La Jolla, CA, USA) according to the multitarget single hit model. The radiation-associated parameters, mean lethal dose (D0) and quasi-threshold dose (Dq), were calculated to evaluate the effect of drug pretreatment on the radiosensitivity of GC cells.

Determination of half maximal inhibitory concentration $\left(I C_{50}\right)$. Determination of the $\mathrm{IC}_{50}$ of NU7441 treatment of GC cells was performed using Cell Counting Kit-8 (CCK-8; Dojindo Molecular Technologies, Inc., Kumamoto, Japan). Briefly, following treatment with increasing concentrations of $\operatorname{NU} 7441(5,10,15$ and $20 \mu \mathrm{M})$ for $48 \mathrm{~h}, 10 \mu \mathrm{l} \mathrm{CCK}-8$ solution was added to each well and incubated for $2 \mathrm{~h}$. Subsequently, the cells were transferred into another 96-well plate and the absorbance was detected at $450 \mathrm{~nm}$ using a microplate reader (Bio-Rad Laboratories, Inc.) to reflect cell viability. The $\mathrm{IC}_{50}$ was calculated using CompuSyn software version 1.0 (ComboSyn, Inc., Paramus, NJ, USA).

Western blot analysis. Cell extracts were prepared in radioimmunoprecipitation assay lysis buffer (Sigma-Aldrich; Merck KGaA, Darmstadt, Germany) and the concentration was measured using a Pierce BCA Protein Assay kit
(Sigma-Aldrich; Merck KGaA) according to the manufacturer's protocol. Briefly, each sample (20 $\mu \mathrm{g}$ protein), prepared with loading buffer, was separated by SDS-PAGE on $8 \%$ gels and electrotransferred onto polyvinylidene difluoride membranes (EMD Millipore, Billerica, MA, USA). Membranes were blocked in $5 \%$ non-fat milk for $1 \mathrm{~h}$ at room temperature and incubated with primary antibody at $4{ }^{\circ} \mathrm{C}$ overnight. GAPDH primary antibody (cat. no. G8795; 1:5,000) was purchased from Sigma-Aldrich (Sigma-Aldrich; Merck KGaA), $\gamma \mathrm{H} 2 \mathrm{~A}$ histone family member $\mathrm{X}(\gamma \mathrm{H} 2 \mathrm{AX}$; cat. no. 33686; 1:1,000), poly [ADP-ribose] polymerase 1 (PARP1; cat. no. 31288; 1:1,000) and caspase3 (cat. no. 29034; 1:1,000) primary antibodies were from Signalway Antibody LLC (College Park, MD, USA). The membranes were then washed with three times with Tris-buffered saline and incubated with a horseradish peroxidase-conjugated secondary antibody (cat. no. 7074, 1:10,000; Cell Signaling Technology, Inc., Danvers, MA, USA) for $2 \mathrm{~h}$. Finally, the blots were visualized using enhanced chemiluminescence (EMD Millipore) and the semi-quantification of bands was performed using ImageJ (version 1.51; National Institutes of Health, Bethesda, MD, USA).

Immunostaining analysis. Cells were incubated with $3 \% \mathrm{H}_{2} \mathrm{O}_{2}$ for $10 \mathrm{~min}$, permeabilized with $0.3 \%$ Triton $\mathrm{X}-100$ in PBS for $15 \mathrm{~min}$ and blocked with $10 \%$ goat serum for $1 \mathrm{~h}$ at room temperature. The sections were then incubated with primary antibody ( $\gamma \mathrm{H} 2 \mathrm{AX}$; cat. no. 33686; $1: 100)$ at $4^{\circ} \mathrm{C}$ overnight. The next day, sections were washed, incubated with biotinylated goat anti-rabbit IgG (cat. no. BA-1000; 1:10,000; Vector Laboratories, Inc., Burlingame, CA, USA) in PBS for $1 \mathrm{~h}$ at room temperature and with VECTASTAIN (PK-6200; Vector Laboratories, Inc.) for $1 \mathrm{~h}$. A horseradish peroxidase reaction product was visualized using an enhanced DAB peroxidase substrate kit (cat. no. SK-4100; Vector Laboratories, Inc.). Immunostaining signals were analyzed using the optical fractionator method with Microbrightfield Stereo-Investigator (MBF Bioscience, Williston, VT, USA). The total number of cells in four or five fields of view was counted per sample.

Statistical analysis. Data are presented as the mean \pm standard deviation. Comparisons between two groups were evaluated by the Student's t-test, and comparisons among multiple groups were analyzed by analysis of variance followed by Newman-Keuls post-hoc analysis using GraphPad Prism 7 software (GraphPad Software, Inc.). $\mathrm{P}<0.05$ was considered to indicate a statistically significant difference.

\section{Results}

$B G C 823$ and MGC803 cell lines are relatively resistant to $I R$. In the present study, six human GC cell lines, SGC7901, HGC-27, MKN45, MKN74, BGC823 and MGC803, were used, and the relative sensitivities to IR were determined by clonogenic survival assay. BGC823 and MGC803 cells were the most resistant to IR, with higher D0 and Dq values (Fig. 1A and Table I). In addition, the expression levels of key regulators involved in cell apoptosis and cell survival were detected in all cell lines treated with IR. The expression levels of cleaved caspase 3 and $\gamma \mathrm{H} 2 \mathrm{AX}$ were relatively low in 
Table I. D0 and Dq of six gastric cancer cell lines towards ionizing radiation.

\begin{tabular}{lcccccc}
\hline Parameter & SGC7901 & HGC-27 & MKN-45 & MKN-28 & BGC-823 & MGC-803 \\
\hline $\operatorname{lnN}$ & 0.689641 & 0.822859 & 0.266203 & 0.524137 & 0.431782 & 0.66114 \\
D0 & 2.795639 & 2.497502 & 3.273322 & 3.303601 & 4.539265 & 3.863988 \\
Dq & 1.927987 & 2.055092 & 0.871368 & 1.731538 & 1.959975 & 2.554638 \\
\hline
\end{tabular}

$\operatorname{lnN}$, ln extrapolation number; D0, mean lethal dose; Dq, quasi-threshold dose.
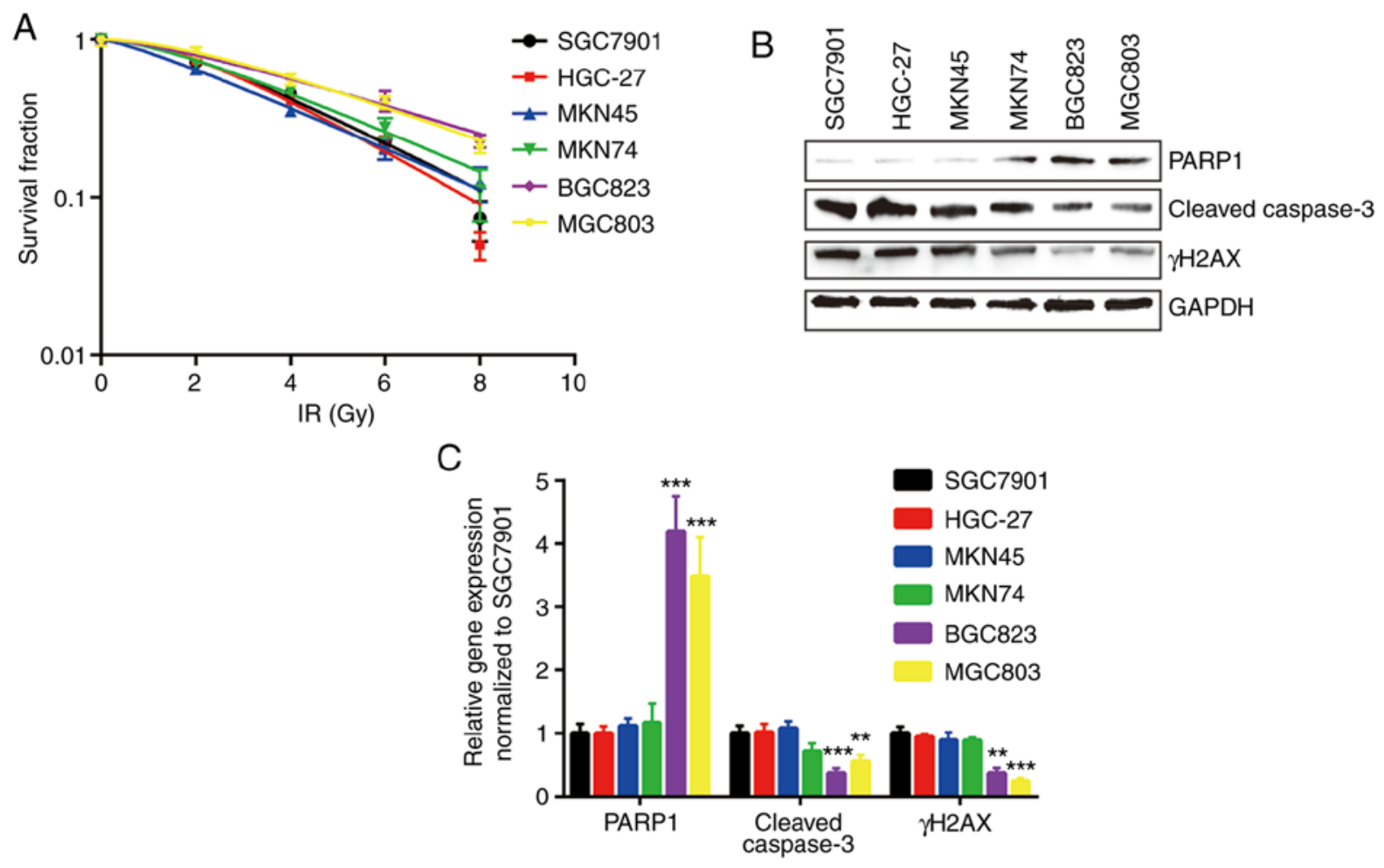

Figure 1. BGC823 and MGC803 cells are relatively insensitive to IR. (A) Six gastric cancer cell lines (SGC7901, HGC-27, MKN45, MKN74, BGC823 and MGC803) were exposed to increasing doses of IR (0, 2, 4, 6 and 8 Gy). (B) Protein expression levels of $\gamma \mathrm{H} 2 \mathrm{AX}$ and cleaved-caspase 3 were decreased, and PARP1 protein expression was increased, in BGC823 and MGC803 cells following IR (4 Gy). (C) Quantification of protein expression levels. * P<0.01 and ${ }^{* * *} \mathrm{P}<0.0001$ vs. SGC7901. IR, ionizing radiation; PARP1, poly [ADP-ribose] polymerase $1 ; \gamma \mathrm{H} 2 \mathrm{AX}, \gamma \mathrm{H} 2 \mathrm{~A}$ histone family member X.

BGC823 and MGC803 cells compared with other cell lines following IR. PARP1, the substrate of active caspase3, was expressed at a relatively high level in BGC823 and MGC803 cells (Fig. 1B and C).

To further evaluate their response to IR, immunofluorescence was used to observe $\gamma \mathrm{H} 2 \mathrm{AX}$ expression following IR treatment. BGC823 cells exhibited weak fluorescence signals compared with MKN45 cells, indicating a mild double strand break induced by IR (Fig. 2A and B).

Overexpression of DNA-PKcs and its phosphorylated form in BGC823 and MGC803 cells. The expression of DNA-PKcs, whose expression predicts response to radiotherapy in various types of cancers, is responsible for DNA repair $(12,19)$. Western blotting detection of DNA-PKcs and p-DNA-PKcs proteins indicated that DNA-PKcs was expressed more highly in BGC823 and MGC803 cells compared with other GC cell lines (Fig. 3A and B).
Inhibition of DNA-PKcs sensitizes BGC823 and MGC803 cells towards IR. To determine whether DNA-PKcs were responsible for different sensitivities towards IR, NU7441 (a DNA-PKcs inhibitor) was used to inhibit DNA-PKcs activity. Cell viability assays revealed that the $\mathrm{IC}_{50}$ was $3.724 \mu \mathrm{M}$ and $4.704 \mu \mathrm{M}$ for $\mathrm{BGC} 823$ and $\mathrm{MGC} 803$, respectively (Fig. 4A). At a very low concentration without significant growth inhibitory effect, $0.1 \mu \mathrm{M}$ NU7441 induced a decreased survival fraction in response to IR compared with cells treated with DMSO in both BGC823 and MGC803 cells (Fig. 4B and C; Table II). In addition, NU7441 treatment increased $\gamma \mathrm{H} 2 \mathrm{AX}$ and cleaved-caspase 3 protein expression levels in BGC823 and MGC803 cells treated with IR (Fig. 4D and E); $0.1 \mu \mathrm{M}$ NU7441 significantly elevated IR induced cell apoptosis of BGC823 and MGC803 cells (Fig. 4F and G). Furthermore, immunofluorescence analysis confirmed an elevation of $\gamma \mathrm{H} 2 \mathrm{AX}$ expression in the nucleus in cells treated with NU7441 after 
A

MKN45
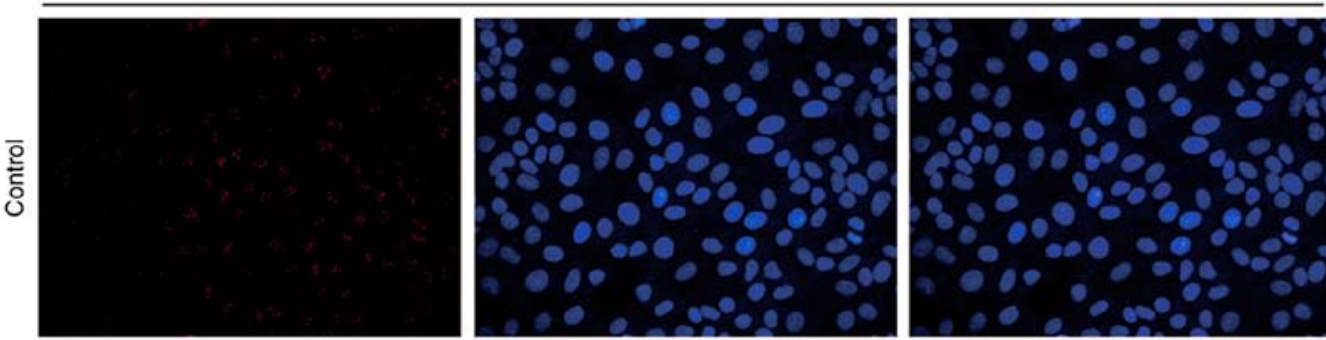

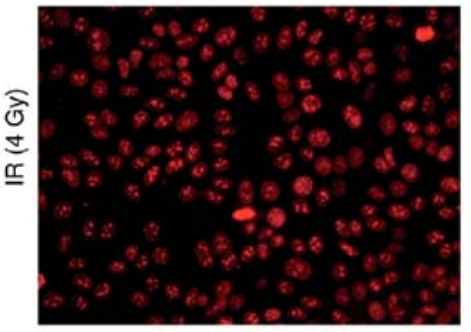

$\gamma \mathrm{H} 2 \mathrm{AX}$

B
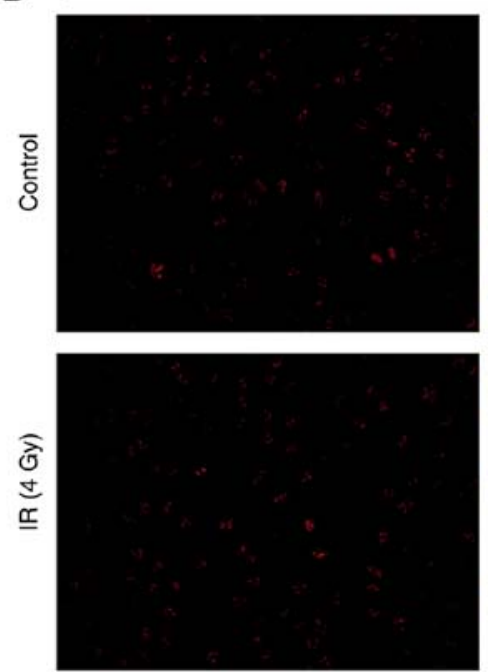

$\gamma \mathrm{H} 2 \mathrm{AX}$

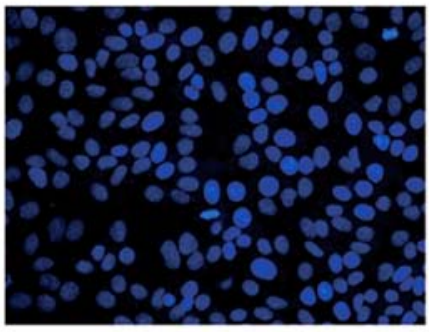

DAPI

BGC823
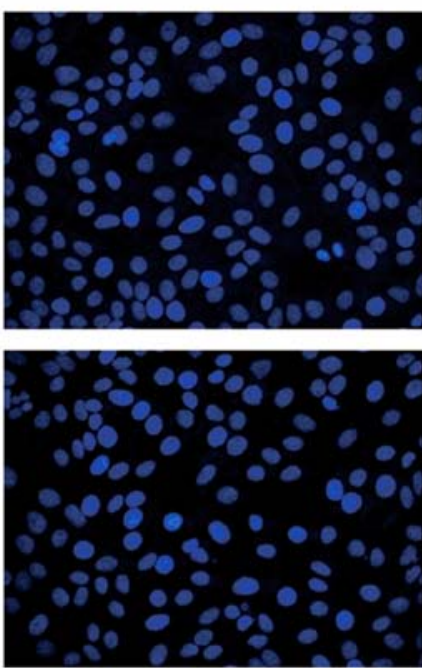

DAPI

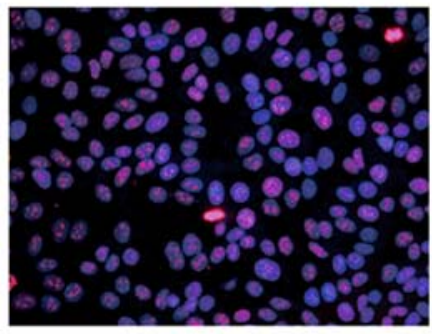

Merge
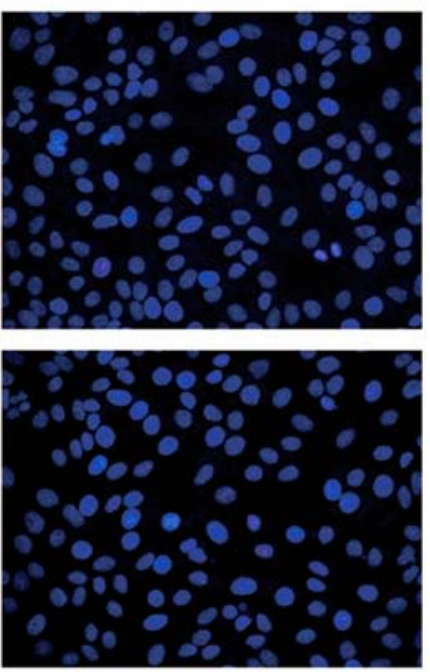

Merge

Figure 2. IR induces elevation of $\gamma \mathrm{H} 2 \mathrm{AX}$ expression in MKN45 cells compared with BGC823 cells. (A) IR (4 Gy) induced $\gamma \mathrm{H} 2 \mathrm{AX}$ expression in the nucleus of MKN45 cells. (B) IR (4 Gy) did not induce $\gamma \mathrm{H} 2 \mathrm{AX}$ expression in the nucleus of BGC823 cells. IR, ionizing radiation; $\gamma \mathrm{H} 2 \mathrm{AX}, \gamma \mathrm{H} 2 \mathrm{~A}$ histone family member X.
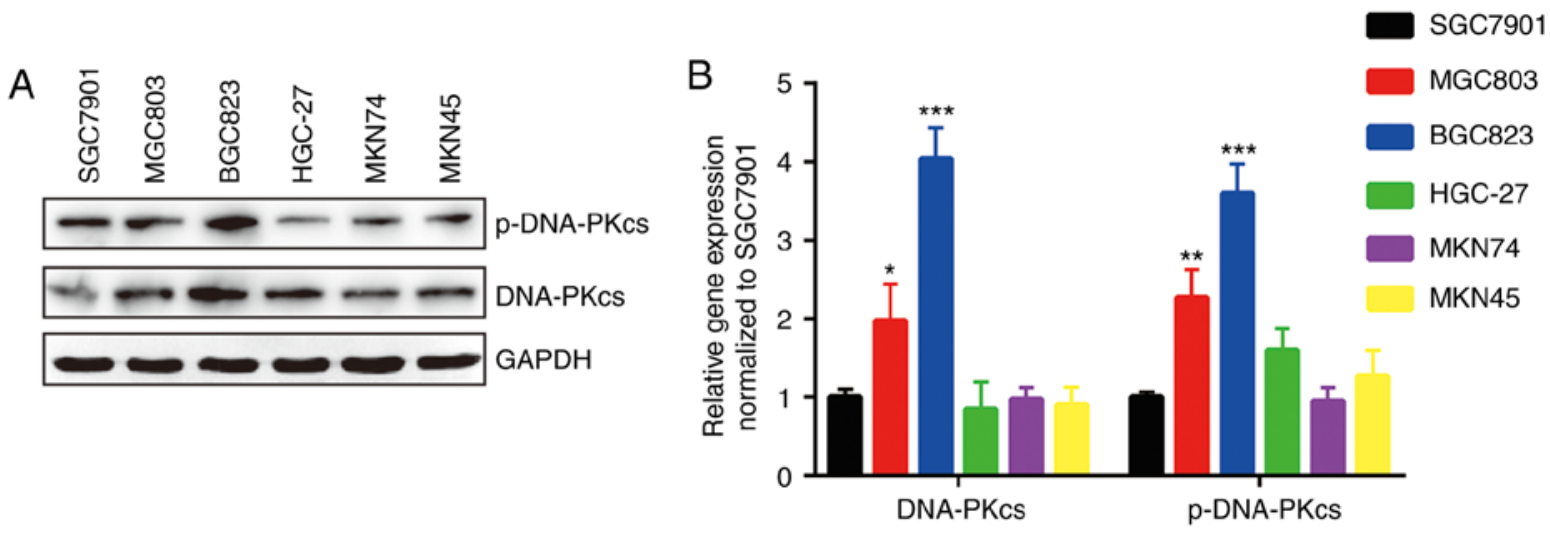

Figure 3. DNA-PKcs and p-DNA-PKcs protein expression levels are relatively high in BGC823 and MGC803 cells compared with other GC cell lines. (A) Western blotting showed that the protein levels of DNA-PKcs and p-DNA-PKcs were relatively high in BGC823 and MGC803 cells compared with other GC cell lines (SGC7901, HGC-27, MKN45 and MKN74 cells). (B) Quantification of protein levels. The protein expression levels of DNA-PKcs and p-DNA-PKcs in BGC823 and MGC803 cells were compared with those of SGC7901. ${ }^{*} \mathrm{P}<0.05,{ }^{* *} \mathrm{P}<0.01,{ }^{* * * *} \mathrm{P}<0.0001$ vs. SGC7901. GC, gastric cancer; DNA-PKcs, DNA-dependent protein kinase catalytic subunit; p-, phospho-. 

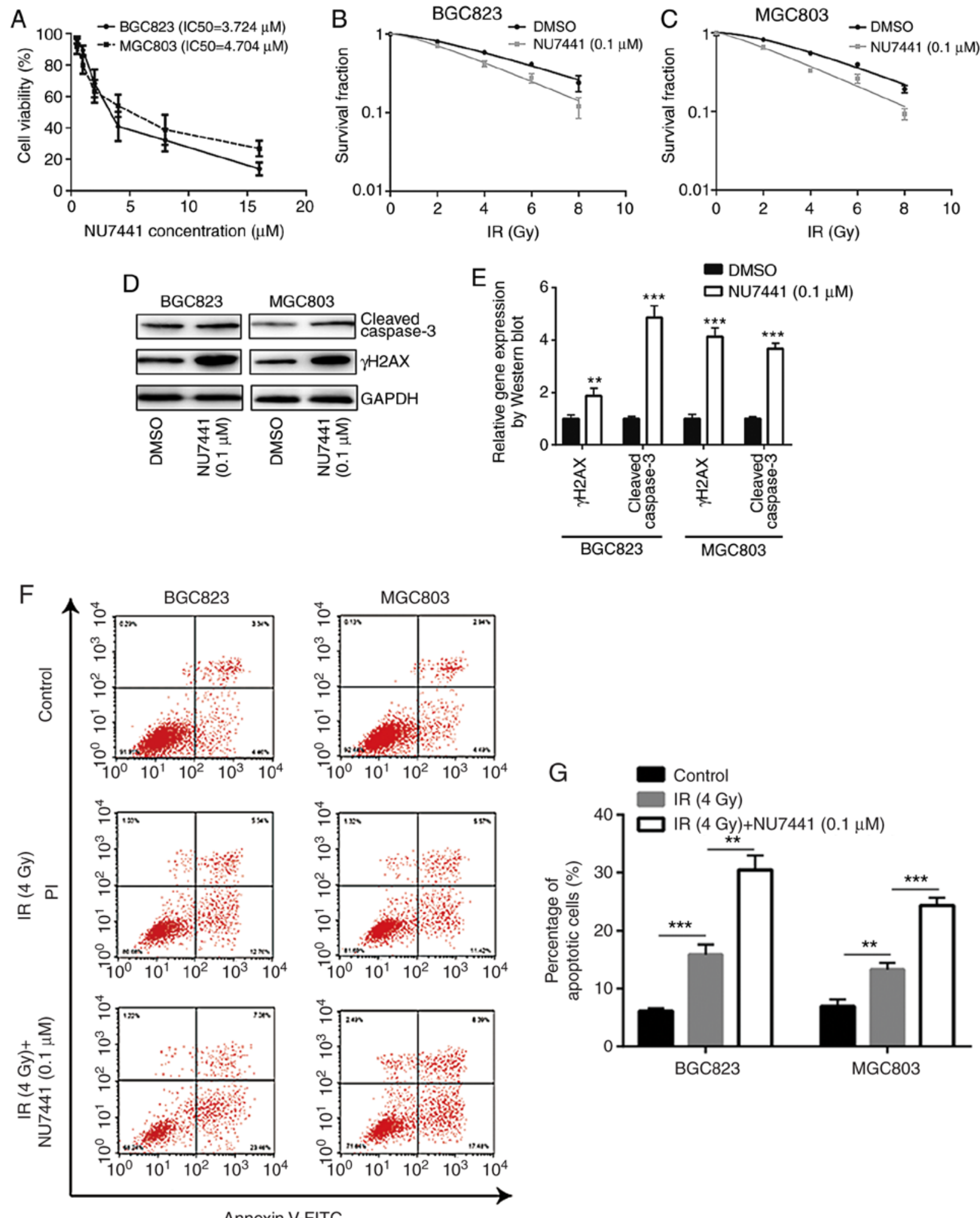

Figure 4. DNA-PKcs inhibition increases the sensitivity of BGC823 and MGC803 cells to IR. (A) BGC823 and MGC803 cells were exposed to increasing concentrations of NU7441 (a DNA-PKcs inhibitor) and the $\mathrm{IC}_{50}$ was calculated. (B) BGC823 and (C) MGC803 cells treated with or without NU7441 (0.1 $\mu \mathrm{M}$ ) were exposed to increasing doses of IR $(0,2,4,6$ and $8 \mathrm{~Gy})$. (D) The protein expression levels of cleaved-caspase 3 and $\gamma \mathrm{H} 2 \mathrm{AX}$ were elevated upon NU7441 $(0.1 \mu \mathrm{M})$ treatment in BGC823 and MGC803 cells following IR (4 Gy). (E) Quantification of protein expression levels. ${ }^{* * *} \mathrm{P}<0.01$ and ${ }^{* * * *} \mathrm{P}<0.0001 \mathrm{vs}$. DMSO (F) NU7441 $(0.1 \mu \mathrm{M})$ significantly elevated IR induced cell apoptosis of BGC823 and MGC803 cells. (G) Quantification of cell apoptotic rates. ${ }^{* * *} \mathrm{P}<0.01$ and ${ }^{* * *} \mathrm{P}<0.0001$. DNA-PKcs, DNA-dependent protein kinase catalytic subunit; DMSO, dimethyl sulfoxide; IR, ionizing radiation; $\gamma \mathrm{H} 2 \mathrm{AX}, \gamma \mathrm{H} 2 \mathrm{~A}$ histone family member X; PI, propidium iodide; FITC, fluorescein isothiocyanate.

IR in BGC823 (Fig. 5A and B). These data collectively demonstrated that DNA-PKcs was involved in radiotherapy sensitivity in GC.
Combination of CK2 inhibitor and DNA-PKcs inhibitor strongly enhances response to radiotherapy in GC cell lines. A previous study indicated that CK2 inhibition could 
Table II. D0 and Dq in BGC823 and MGC803 treated with or without NU7441 $(0.1 \mu \mathrm{M})$ towards ionizing radiation.

\begin{tabular}{lcccr}
\hline & \multicolumn{3}{c}{ BGC823 } & \multicolumn{2}{c}{ MGC803 } \\
\cline { 2 - 3 } Parameter & DMSO & NU7441 & DMSO & NU7441 \\
\hline $\ln N$ & 0.480573 & 0.421338 & 0.677018 & 0.285931 \\
D0 & 4.526935 & 3.402518 & 3.762227 & 3.30142 \\
Dq & 2.175521 & 1.433612 & 2.547095 & 0.943977 \\
\hline
\end{tabular}

$\operatorname{lnN}$, ln extrapolation number; D0, mean lethal dose; Dq, quasi-threshold dose.

Table III. Comparison of D0 and Dq of BGC823 and MGC803 treated with NU7441 $(0.1 \mu \mathrm{M})$ or NU7441 $(0.1 \mu \mathrm{M})$ and CX4945 $(0.5 \mu \mathrm{M})$ towards ionizing radiation.

\begin{tabular}{|c|c|c|c|c|}
\hline \multirow[b]{2}{*}{ Parameter } & \multicolumn{2}{|c|}{ BGC823 } & \multicolumn{2}{|c|}{ MGC803 } \\
\hline & NU7441 & NU7441 + CX4945 & NU7441 & NU7441 + CX4945 \\
\hline $\operatorname{lnN}$ & 0.42853 & 0.295650242 & 0.285931 & 0.104360015 \\
\hline D0 & 3.434066 & 2.849814762 & 3.30142 & 2.748763057 \\
\hline $\mathrm{Dq}$ & 1.471602 & 0.842548424 & 0.943977 & 0.286860955 \\
\hline
\end{tabular}

$\operatorname{lnN}$, ln extrapolation number; D0, mean lethal dose; Dq, quasi-threshold dose.

A

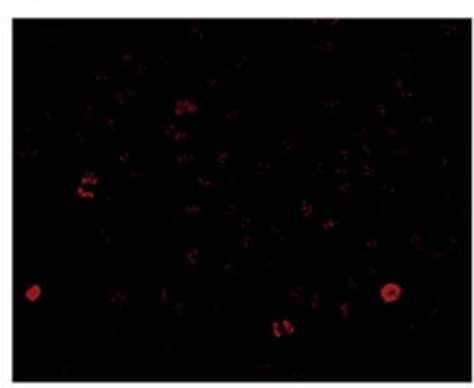

YH2AX

B

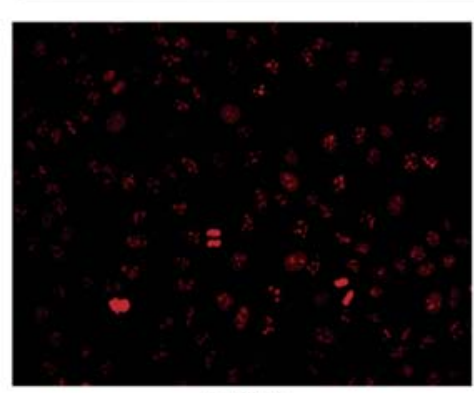

$\gamma \mathrm{H} 2 \mathrm{AX}$
DMSO

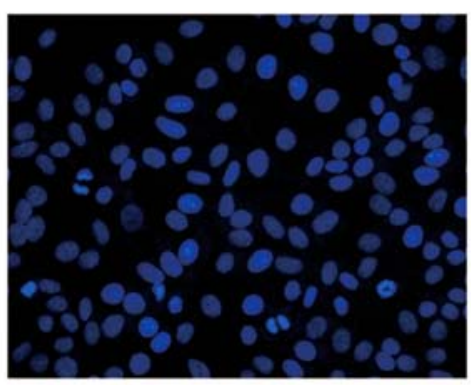

DAPI

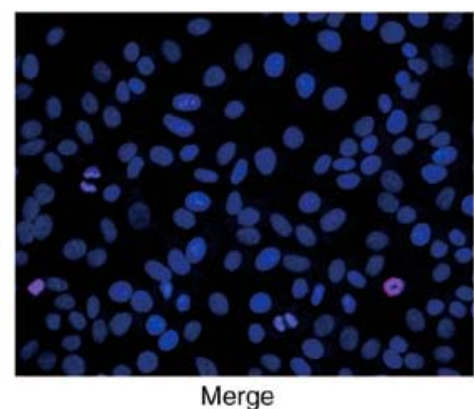

Merge

NU7441 $(0.1 \mu \mathrm{M})$

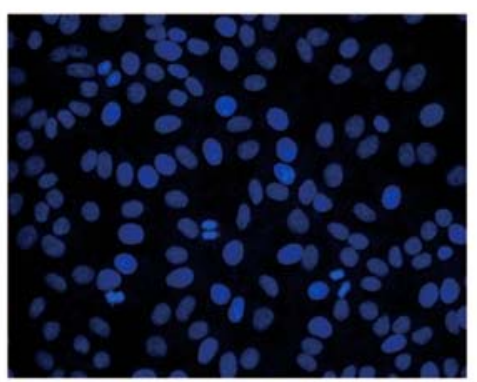

DAPI

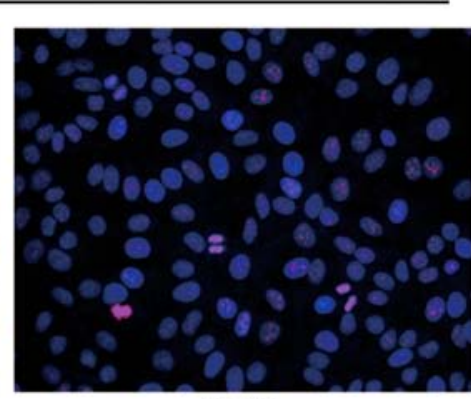

Merge

Figure 5. NU7441 treatment increases $\gamma \mathrm{H} 2 \mathrm{AX}$ expression in the nucleus of BGC823 cells following IR. (A) Representative image of $\gamma \mathrm{H} 2 \mathrm{AX}$ expression in the nucleus of BGC823 cells treated with DMSO and IR (4 Gy). (B) Compared with cells treated with DMSO, NU7441 ( $0.1 \mu \mathrm{M})$ treatment augmented $\gamma \mathrm{H} 2 \mathrm{AX}$ expression in the nucleus of BGC823 cells following IR (4 Gy). IR, ionizing radiation; $\gamma \mathrm{H} 2 \mathrm{AX}, \gamma \mathrm{H} 2 \mathrm{~A}$ histone family member X; DMSO, dimethyl sulfoxide.

increase radiotherapy sensitivity via inhibition of $\mathrm{X}$-ray repair cross complementing 1 (XRCC1) (20). In BGC823 and MGC803 cells, the combination of CK2 inhibitor (CX-4945) and DNA-PKcs inhibitor (NU7441), demonstrated a stronger enhancing effect in radiotherapy sensitivity compared with NU7441 alone (Fig. 6A and B; Table III). Furthermore, the 

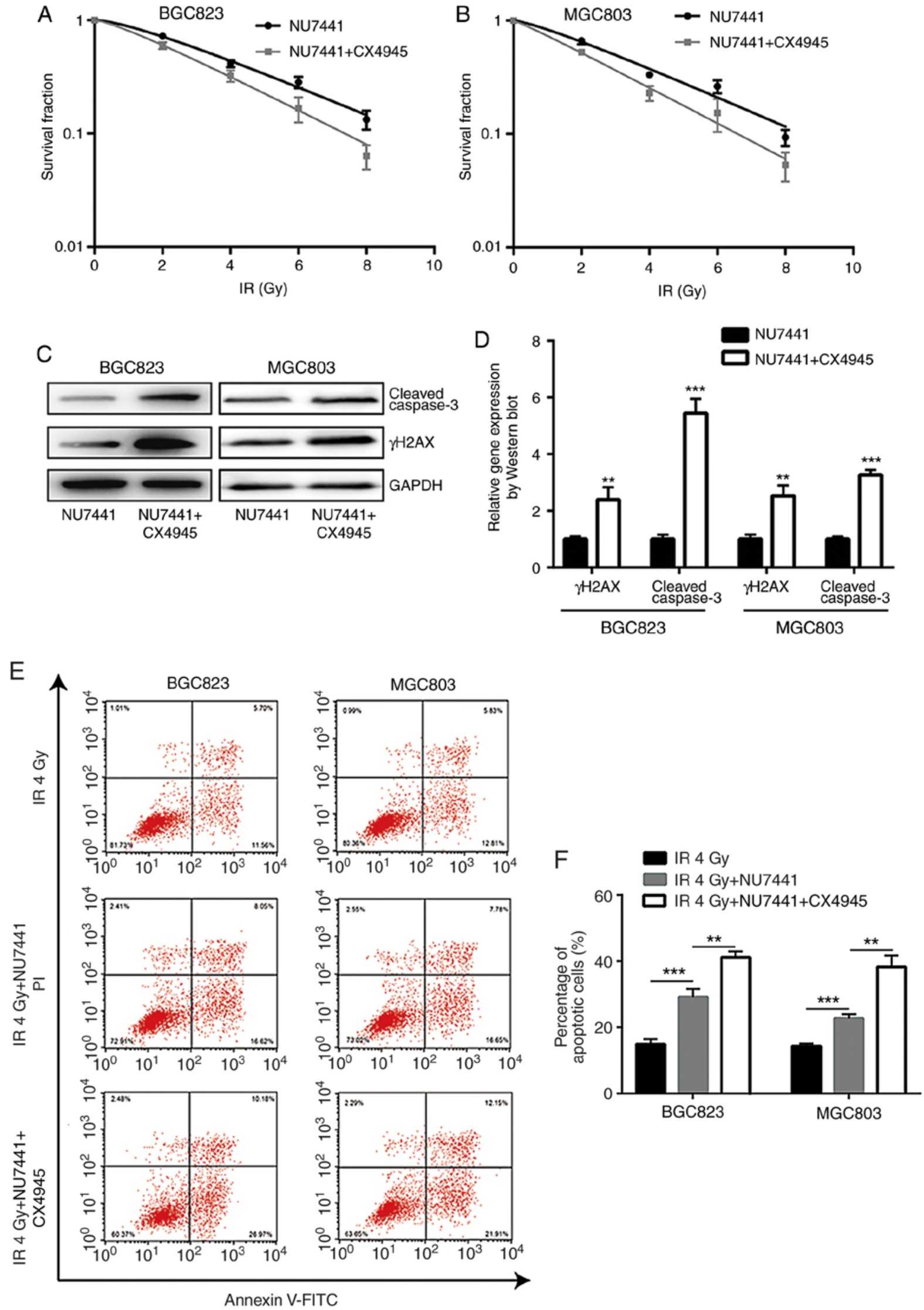

Figure 6. Combination of DNA-dependent protein kinase catalytic subunit inhibition and CK2 inhibition further increases sensitivity of gastric cancer cells to IR. (A) BGC823 and (B) MGC803 cells treated with NU7441 $(0.1 \mu \mathrm{M})$, or a combination of NU7441 $(0.1 \mu \mathrm{M})$ and CX4945 $(0.5 \mu \mathrm{M}$; a CK2 inhibitor), were exposed to increasing doses of IR $(0,2,4,6$ and $8 \mathrm{~Gy})$. (C) Western blotting showed that the combination of NU7441 $(0.1 \mu \mathrm{M})$ and $\mathrm{CX} 4945(0.5 \mu \mathrm{M})$ induced a significant elevation of cleaved-caspase 3 and $\gamma \mathrm{H} 2 \mathrm{AX}$ protein expression levels compared with treatment with NU7441 $(0.1 \mu \mathrm{M})$ alone in BGC823 and MGC803 cells. (D) Quantification of protein expression levels. ${ }^{* *} \mathrm{P}<0.01$ and ${ }^{* * *} \mathrm{P}<0.0001$ vs. NU7441. (E) CX4945 further significantly elevated NU7441 induced cell apoptosis of GC823 cells and MGC803 cells. (F) Quantification of cell apoptosis rates. ${ }^{* * *} \mathrm{P}<0.01$ and ${ }^{* * * *} \mathrm{P}<0.0001$. CK2, casein kinase 2; IR, ionizing radiation; $\gamma \mathrm{H} 2 \mathrm{AX}, \gamma \mathrm{H} 2 \mathrm{~A}$ histone family member X; PI, propidium iodide; FITC, fluorescein isothiocyanate. 


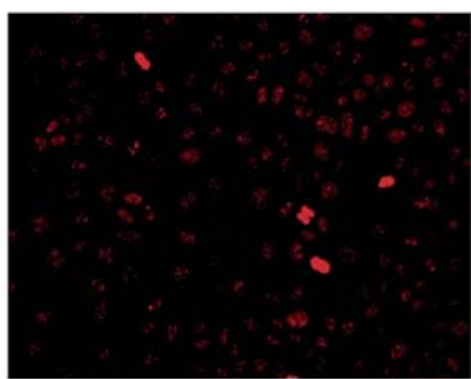

$\gamma H 2 A X$

B

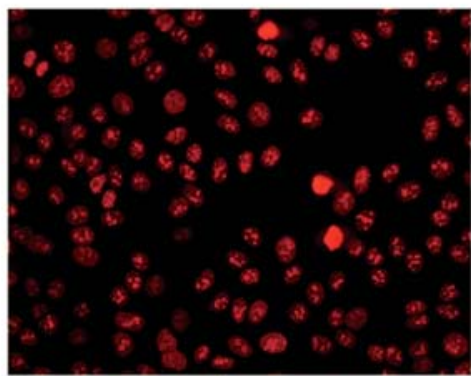

$\gamma \mathrm{H} 2 \mathrm{AX}$

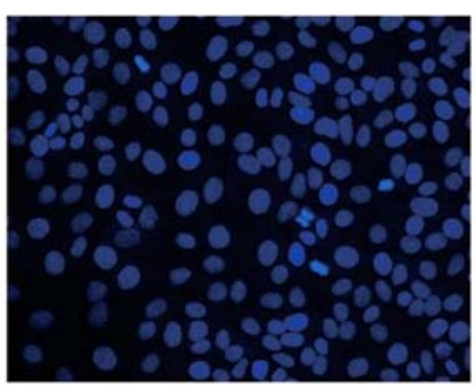

DAPI

NU7441+CX4945

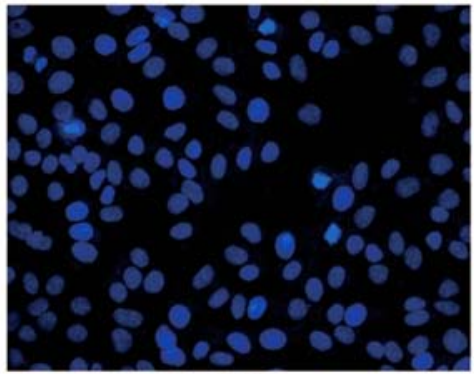

DAPI

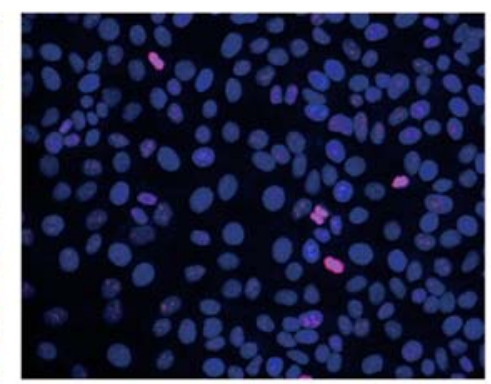

Merge

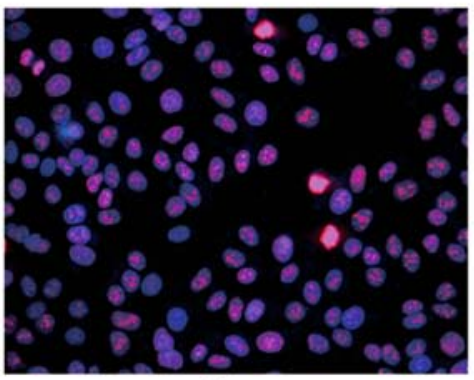

Merge

Figure 7. Combination of NU7441 and CX4945 treatment increases $\gamma \mathrm{H} 2 \mathrm{AX}$ expression in nucleus of BGC823 cells following IR compared with single treatment of NU7441. (A) Representative image of $\gamma \mathrm{H} 2 \mathrm{AX}$ expression in the nucleus of BGC823 cells treated with NU7441 (0.1 $\mu \mathrm{M})$ following IR (4 Gy). (B) Combination of NU7441 $(0.1 \mu \mathrm{M})$ and CX4945 $(0.5 \mu \mathrm{M})$ induced strong expression of $\gamma \mathrm{H} 2 \mathrm{AX}$ in the nucleus of BGC823 cells following IR (4 Gy). IR, ionizing radiation; $\gamma \mathrm{H} 2 \mathrm{AX}, \gamma \mathrm{H} 2 \mathrm{~A}$ histone family member $\mathrm{X}$.

combination of CX-4945 and NU7441 further increased $\gamma \mathrm{H} 2 \mathrm{AX}$ and cleaved-caspase 3 protein expression levels in both cell lines (Fig. 6C and D); additionally, CX4945 further significantly elevated NU7441 induced cell apoptosis of GC823 cells and MGC803 cells (Fig. 6E and F). The elevation of $\gamma \mathrm{H} 2 \mathrm{AX}$ expression was validated in an immunofluorescence assay (Fig. 7A and B).

\section{Discussion}

Radiotherapy is one of the standard treatment approaches for GC, and can significantly improve the 5 year survival rate of patients with GC (21). It is important to maximize the therapeutic effect of radiotherapy towards tumor tissues and minimize damage to normal tissues (22). Thus, increasing sensitivity of GC towards radiotherapy may reduce the side effects of radiation. In the current study, inhibition of DNA-PKcs enhanced radiotherapy sensitivity of GC cells. Combination of DNA-PKcs and CK2 inhibition could further augment sensitivity towards radiotherapy.

Activation of DNA-PKcs has been demonstrated to be crucial for DNA double strand break repair (23). As DNA-PKcs is indispensable for DNA damage repair, its expression is an important indicator for response to DNA-damaging agents in various types of cancer $(12,24)$. DNA-PKcs also promotes cancer cell metastasis via transcriptional regulation (25). In GC, the role of DNA-PKcs is controversial. A report demonstrated that the expression of DNA-PKcs was frequently elevated compared with normal gastric tissues and was associated with relatively lower differentiation (26). In another study, loss of DNA-PKcs in GC was associated with advanced cancer, lymphatic invasion, lymph node metastasis and advanced pTNM stage (27). The activity of DNA-PKcs is largely reliant on Ku70/80 and DNA (28). Mechanistically, Ku-DNA complex induces conformation change of phosphoinositide 3-kinase domain to activate DNA-PKcs (29). In human tumor cells, a study revealed that DNA-PKcs activation was also controlled by the Akt serine/threonine kinase pathway. Activated Akt directly interacts with DNA-PKcs to promote DSB accumulation of DNA-PKcs, which would lead to radiotherapy resistance (30). A recent report discovered that microRNA-101 negatively regulates DNA-PKcs and downregulation of microRNA-101 was responsible for overexpression of DNA-PKcs in renal cell carcinoma (31). The function of DNA-PKcs in mediating radiotherapy sensitivity of GC remains unknown. Expression of DNA-PKcs and its active form were increased in GC cell lines that were relatively insensitive towards IR. In addition, inhibition of DNA-PKcs sensitized GC cells exposed to IR, alongside significantly increased expression of $\gamma \mathrm{H} 2 \mathrm{AX}$ and cleaved caspase3.

CK2 is a highly conserved kinase that controls the DNA damage repair regulation process through phosphorylation of its substrates (32). Several reports have indicated that CK2 enhances radiosensitivity of non-small cell lung cancer cells via regulation of XRCC4 $(33,34)$. However, although it modulated DNA damage response, $\mathrm{CK} 2$ inhibition failed to increase radiosensitivity of malignant glioma cells (35). In GC, CK2 expression promoted cancer progression and chemoresistance, 
and predicted poor prognosis $(36,37)$. Inhibition of CK2 activity further increased radiosensitivity of $\mathrm{GC}$ cells treated with DNA-PKcs inhibitor. This indicated that CK2 and DNA-PKcs are both involved in the radiosensitivity of GC cells. A double inhibition strategy using CK2 and DNA-PKcs may be effective in improving the effect of radiotherapy in patients with GC.

In conclusion, the findings of the study revealed that DNA-PKcs expression is important for the sensitivity of GC to radiotherapy. Combination of CK2 and DNA-PKcs inhibition further sensitized GC cells to IR. These results suggest that DNA-PKcs and CK2 may be novel therapeutic targets for enhancing the effect of radiotherapy for patients with GC.

\section{Acknowledgements}

Not applicable.

\section{Funding}

The current study was funded by the Nanjing Military Area Medical Science and Technology Innovation Key Project Funding Project (grant no. 15ZD011) and the Science and Technology Project of Huaian (grant no. HAB201822).

\section{Availability of data and materials}

The datasets used and/or analyzed during the current study are available from the corresponding author on reasonable request.

\section{Authors' contributions}

WG, HS, DT, QW and SS performed the experiments and acquired the data. HS, JZ and WX analyzed the data. HS and WG wrote the paper. WG and HS supervised the current study. All authors read and approved the final manuscript.

\section{Ethics approval and consent to participate}

Not applicable.

\section{Patient consent for publication}

Not applicable.

\section{Competing interests}

The authors declare that they have no competing interests.

\section{References}

1. Torre LA, Bray F, Siegel RL, Ferlay J, Lortet-Tieulent J and Jemal A: Global cancer statistics, 2012. CA Cancer J Clin 65 87-108, 2015.

2. Yeh JM, Kuntz KM, Ezzati M, Hur C, Kong CY and Goldie SJ: Development of an empirically calibrated model of gastric cancer in two high-risk countries. Cancer Epidemiol Biomarkers Prev 17: 1179-1187, 2008

3. Macdonald JS, Smalley SR, Benedetti J, Hundahl SA, Estes NC, Stemmermann GN, Haller DG, Ajani JA, Gunderson LL, Jessup JM and Martenson JA: Chemoradiotherapy after surgery compared with surgery alone for adenocarcinoma of the stomach or gastroesophageal junction. N Engl J Med 345: 725-730, 2001.
4. Toiyama Y, Tanaka K, Konishi N, Mohri Y, Tonouchi H, Miki C and Kusunoki M: Administration sequence-dependent antitumor effects of paclitaxel and 5-fluorouracil in the human gastric cancer cell line MKN45. Cancer Chemother Pharmacol 57: 368-375, 2006.

5. Hartgrink HH, Jansen EP, van Grieken NC and van de Velde CJ: Gastric cancer. Lancet 374: 477-490, 2009.

6. Valentini V and Cellini F: Radiotherapy in gastric cancer: A systematic review of literature and new perspectives. Expert Rev Anticancer Ther 7: 1379-1393, 2007.

7. Garg AK, Buchholz TA and Aggarwal BB: Chemosensitization and radiosensitization of tumors by plant polyphenols. Antioxid Redox Signal 7: 1630-1647, 2005.

8. Dai Y and Grant S: New insights into checkpoint kinase 1 in the DNA damage response signaling network. Clin Cancer Res 16: 376-383, 2010

9. Liu P, Gan W, Guo C, Xie A, Gao D, Guo J, Zhang J, Willis N, Su A, Asara JM, et al: Akt-mediated phosphorylation of XLF impairs non-homologous end-joining DNA repair. Mol Cell 57: 648-661, 2015

10. Zhang S, Matsunaga S, Lin YF, Sishc B, Shang Z, Sui J, Shih HY, Zhao Y, Foreman O, Story M, et al: Spontaneous tumor development in bone marrow-rescued DNA-PKcs(3A/3A) mice due to dysfunction of telomere leading strand deprotection. Oncogene 35: 3909-3918, 2016

11. Lee SH and Kim CH: DNA-dependent protein kinase complex: A multifunctional protein in DNA repair and damage checkpoint. Mol Cells 13: 159-166, 2002

12. Bouchaert P, Guerif S, Debiais C, Irani J and Fromont G: DNA-PKcs expression predicts response to radiotherapy in prostate cancer. Int J Radiat Oncol Biol Phys 84: 1179-1185, 2012.

13. Peng Y, Zhang Q, Nagasawa H, Okayasu R, Liber HL and Bedford JS: Silencing expression of the catalytic subunit of DNA-dependent protein kinase by small interfering RNA sensitizes human cells for radiation-induced chromosome damage, cell killing, and mutation. Cancer Res 62: 6400-6404, 2002.

14. Toulany M, Kehlbach R, Florczak U, Sak A, Wang S, Chen J, Lobrich M and Rodemann HP: Targeting of AKT1 enhances radiation toxicity of human tumor cells by inhibiting DNA-PKcs-dependent DNA double-strand break repair. Mol Cancer Ther 7: 1772-1781, 2008.

15. Lee SW, Cho KJ, Park JH, Kim SY, Nam SY, Lee BJ, Kim SB, Choi SH, Kim JH, Ahn SD, et al: Expressions of Ku70 and DNA-PKcs as prognostic indicators of local control in nasopharyngeal carcinoma. Int J Radiat Oncol Biol Phys 62: 1451-1457, 2005.

16. Bjork-Eriksson T, West C, Nilsson A, Magnusson B, Svensson M, Karlsson E, Slevin N, Lewensohn R and Mercke C: The immunohistochemical expression of DNA-PKCS and $\mathrm{Ku}(\mathrm{p} 70 / \mathrm{p} 80)$ in head and neck cancers: Relationships with radiosensitivity. Int J Radiat Oncol Biol Phys 45: 1005-1010, 1999.

17. Eriksson A, Lewensoh R, Larsson R and Nilsson A: DNA-dependent protein kinase in leukaemia cells and correlation with drug sensitivity. Anticancer Res 22: 1787-1793, 2002.

18. Tu Y, Ji C, Yang B, Yang Z, Gu H, Lu CC, Wang R, Su ZL, Chen B, Sun WL, et al: DNA-dependent protein kinase catalytic subunit (DNA-PKcs)-SIN1 association mediates ultraviolet B (UVB)-induced Akt Ser-473 phosphorylation and skin cell survival. Mol Cancer 12: 172, 2013.

19. Xu JY, Lu S, Xu XY, Hu SL, Li B, Qi RX, Chen L and Chang JY: Knocking down nucleolin expression enhances the radiosensitivity of non-small cell lung cancer by influencing DNA-PKcs activity. Asian Pac J Cancer Prev 16: 3301-3306, 2015.

20. Strom CE, Mortusewicz O, Finch D, Parsons JL, Lagerqvist A, Johansson F, Schultz N, Erixon K, Dianov GL and Helleday T: CK2 phosphorylation of XRCC1 facilitates dissociation from DNA and single-strand break formation during base excision repair. DNA Repair (Amst) 10: 961-969, 2011.

21. Zhang ZX, Gu XZ, Yin WB, Huang GJ, Zhang DW and Zhang RG: Randomized clinical trial on the combination of preoperative irradiation and surgery in the treatment of adenocarcinoma of gastric cardia (AGC)-report on 370 patients. Int J Radiat Oncol Biol Phy 42: 929-934, 1998.

22. Moran JM, Elshaikh MA and Lawrence TS: Radiotherapy: What can be achieved by technical improvements in dose delivery? Lancet Oncol 6: 51-58, 2005.

23. Kurimasa A, Kumano S, Boubnov NV, Story MD, Tung CS, Peterson SR and Chen DJ: Requirement for the kinase activity of human DNA-dependent protein kinase catalytic subunit in DNA strand break rejoining. Mol Cell Biol 19: 3877-3884, 1999. 
24. Beskow C, Skikuniene J,Holgersson A, Nilsson B, Lewensohn R, Kanter $\mathrm{L}$ and Viktorsson K: Radioresistant cervical cancer shows upregulation of the NHEJ proteins DNA-PKcs, Ku70 and Ku86. Br J Cancer 101: 816-821, 2009.

25. Goodwin JF, Kothari V, Drake JM, Zhao S, Dylgjeri E, Dean JL, Schiewer MJ, McNair C, Jones JK, Aytes A, et al: DNA-PKcs-mediated transcriptional regulation drives prostate cancer progression and metastasis. Cancer Cell 28: 97-113, 2015.

26. Li W, Xie C, Yang Z, Chen J and Lu NH: Abnormal DNA-PKcs and $\mathrm{Ku} 70 / 80$ expression may promote malignant pathological processes in gastric carcinoma. World J Gastroenterol 19: 6894-6901, 2013.

27. Lee HS, Yang HK, Kim WH and Choe G: Loss of DNA-dependent protein kinase catalytic subunit (DNA-PKcs) expression in gastric cancers. Cancer Res Treat 37: 98-102, 2005.

28. Hammarsten $\mathrm{O}$ and Chu G: DNA-dependent protein kinase: DNA binding and activation in the absence of $\mathrm{Ku}$. Proc Nat Acad Sci USA 95: 525-530, 1998.

29. Rivera-Calzada A, Maman JD, Spagnolo L, Pearl LH and Llorca O: Three-dimensional structure and regulation of the DNA-dependent protein kinase catalytic subunit (DNA-PKcs). Structure 13: 243-255, 2005.

30. Toulany M, Lee KJ, Fattah KR, Lin YF, Fehrenbacher B, Schaller M, Chen BP, Chen DJ and Rodemann HP: Akt promotes post-irradiation survival of human tumor cells through initiation progression, and termination of DNA-PKcs-dependent DNA double-strand break repair. Mol Cancer Res 10: 945-957, 2012.

31. Zheng B, Mao JH, Li XQ, Qian L, Zhu H, Gu DH and Pan XD: Over-expression of DNA-PKcs in renal cell carcinoma regulates mTORC2 activation, HIF-2 $\alpha$ expression and cell proliferation. Sci Rep 6: 29415, 2016.
32. Meggio F and Pinna LA: One-thousand-and-one substrates of protein kinase CK2? FASEB J 17: 349-368, 2003.

33. Li Q, Li K, Yang T, Zhang S, Zhou Y, Li Z, Xiong J, Zhou F, Zhou X, Liu L, et al: Association of protein kinase CK2 inhibition with cellular radiosensitivity of non-small cell lung cancer. Sci Rep 7: 16134, 2017.

34. Lin YC, Hung MS, Lin CK, Li JM, Lee KD, Li YC, Chen MF, Chen JK and Yang CT: CK2 inhibitors enhance the radiosensitivity of human non-small cell lung cancer cells through inhibition of stat 3 activation. Cancer Biother Radiopharm 26: 381-388, 2011.

35. Kroonen J, Artesi M, Capraro V, Nguyen-Khac MT, Willems M, Chakravarti A, Bours V and Robe PA: Casein kinase 2 inhibition modulates the DNA damage response but fails to radiosensitize malignant glioma cells. Int J Oncol 41: 776-782, 2012.

36. Xu W, Chen Q, Wang Q, Sun Y, Wang S, Li A, Xu S, Røe OD, Wang M, Zhang R, et al: JWA reverses cisplatin resistance via the CK2-XRCC1 pathway in human gastric cancer cells. Cell Death Dis 5: e1551, 2014.

37. Bae JS, Park SH, Kim KM, Kwon KS, Kim CY, Lee HK, Park BH, Park HS, Lee H, Moon WS, et al: CK2alpha phosphorylates $\mathrm{DBC} 1$ and is involved in the progression of gastric carcinoma and predicts poor survival of gastric carcinoma patients. Int J Cancer 136: 797-809, 2015.

This work is licensed under a Creative Commons Attribution-NonCommercial-NoDerivatives 4.0 International (CC BY-NC-ND 4.0) License. 